\title{
MAGNETIC RESONANCE IMAGING IN SPINAL TUMOURS AND ITS HISTOPATHOLOGICAL CORRELATION
}

\author{
Pankaj Yadav1, Avinash Sharma², J. S. Sikarwar³, Swati Goyal4, Vivek Kumar Soni'5, Meenal Chandravanshi ${ }^{6}$ \\ ${ }^{1}$ Associate Professor, Department of Radiodiagnosis, G. R. Medical College and J. A. Group of Hospitals, Gwalior. \\ ${ }^{2}$ Associate Professor, Department of Neurosurgery, G. R. Medical College and J. A. Group of Hospitals, Gwalior. \\ ${ }^{3}$ Associate Professor, Department of Radiodiagnosis, G. R. Medical College and J. A. Group of Hospitals, Gwalior. \\ ${ }^{4}$ Assistant Professor, Department of Radiodiagnosis, G. R. Medical College and J. A. Group of Hospitals, Gwalior. \\ ${ }^{5}$ Postgraduate Resident, Department of Radiodiagnosis, G. R. Medical College and J. A. Group of Hospitals, Gwalior. \\ ${ }^{6}$ Postgraduate Resident, Department of Radiodiagnosis, G. R. Medical College and J. A. Group of Hospitals, Gwalior.
}

\section{ABSTRACT}

\section{BACKGROUND}

The potential of MRI in the evaluation of suspected neoplasms of the spinal cord is highly recognised. With the advent of surface coils and improved imaging techniques, the superiority of MRI over myelography and post-myelography Computed Tomography (CT) in the assessment of intramedullary tumours was established. MRI also proved to be as efficacious as the traditional modalities in the evaluation of suspected extradural tumour impinging on the thecal sac. With the advent of contrast agents, MRI proved to be at least as effective as myelography and post-myelography CT in the evaluation of suspected intradural extramedullary tumours.

\section{MATERIALS AND METHODS}

This prospective study was conducted in the department of radiodiagnosis, G. R. Medical College and J. A. Group of Hospitals in collaboration with Vidya MRI Centre, Gwalior in suspected spinal tumours and their histopathological correlation done. All patients were referred for MR, because of clinical presentations including backache and/or neurological deficits from the Departments of Orthopaedics, Neurology and Neurosurgery. Patient population included both males and females.

\section{RESULTS}

The present study includes 77 patients of spinal tumours in our own institute during last one year and were correlated with histopathological findings. The tissue specimen for histopathological diagnosis was obtained by FNAC/biopsy/surgical excision and all cases had confirmed histological diagnosis, except for cases of haemangioma. Of the 77 patients 61 patients showed extradural tumours, 12 patients showed intradural extramedullary tumour and 4 patients showed intramedullary tumours. In extradural tumours, metastases were the most common tumours followed by multiple myeloma. In intradural extramedullary tumours, nerve sheath tumours were most common (7 cases of 12) followed by meningiomas (3 cases of 12). In intramedullary tumours, astrocytoma was found in 2 patients and ependymoma was found in 2 patients. Overall, haemangiomas were the most common incidental finding.

\section{CONCLUSION}

MRI of the spine is highly accurate, non-invasive method for the evaluation of spinal tumours, especially intradural extramedullary and intramedullary tumours. MRI clearly shows whether the space occupying lesion is extradural, intradural, extramedullary or intramedullary. Based on the signal intensity characterisation, MRI can be very accurate in tissue characterisation of a tumour. Gadolinium - DTPA contrast scans are very helpful in the characterisation of tumour. Gadolinium DTPA is also helpful for detection of the tumour nidus, which is very essential to direct surgery towards accurate removal of the same.

\section{KEYWORDS}

Magnetic Resonance Imaging, Spinal, Tumours.

HOW TO CITE THIS ARTICLE: Yadav P, Sharma A, Sikarwar JS, et al. Magnetic resonance imaging in spinal tumours and its histopathological correlation. J. Evolution Med. Dent. Sci. 2016;5(104):7616-7622, DOI: 10.14260/jemds/2016/1721

\section{BACKGROUND}

Of all areas of spinal pathology, it may be in the field of spinal tumours that Magnetic Resonance Imaging (MRI) has had the most impact. Almost immediately after its inception, even with the poor quality of early scans, the potential of MRI in the evaluation of suspected neoplasms of the cord was recognised.

Financial or Other, Competing Interest: None.

Submission 30-08-2016, Peer Review 22-10-2016,

Acceptance 28-10-2016, Published 29-12-2016.

Corresponding Author:

Dr. Pankaj Yadav,

Associate Professor,

Department of Radiodiagnosis,

G. R. Medical College \&

J. A. Group of Hospitals, Gwalior.

E-mail: pankajrad71@yahoo.com

DOI: $10.14260 /$ jemds $/ 2016 / 1721$
With the advent of surface coils and improved imaging techniques, the superiority of MRI over myelography and postmyelography Computed Tomography (CT) in the assessment of intramedullary tumours was established. MRI also proved to be as efficacious as the traditional modalities in the evaluation of suspected extradural tumour impinging on the thecal sac. With the advent of contrast agents, MRI proved to be at least as effective as Myelography and postmyelography CT in the evaluation of suspected intradural extramedullary tumours.

Spinal tumours are often categorised as extradural, intradural, extramedullary or intramedullary in location. This classification represents somewhat of an overgeneralisation for two reasons. First, a given lesion may reside in two compartments simultaneously. For example, a neurofibroma in one case may be dumbbell-shaped and extend into both the extradural and the intradural-extramedullary spaces. Second, 
in different cases, two lesions with identical pathology may occur in different compartments. For example, neurofibromas may occur in any of the three compartments including the intramedullary space. Nevertheless, this classification scheme is useful, because it is traditional and helps to characterise spinal tumours.

In the extradural space, numerous primary bone tumours can occur. Secondary tumours or metastases are far more common in the extradural space.

In the intradural extramedullary space, primary tumours such as neurofibroma and meningioma are relatively common.

Finally, in the intramedullary space, primary tumours are far more common than secondary tumours or metastasis. Spinal tumours form one of the most important groups of diseases among the neurosurgical cases. Though the incidence of mortality is very low, early detection and treatment is very essential to prevent morbidity. With the rapid advancement occurring in the field of technology, Radiology is playing an important role in the diagnosis and characterisation of spinal tumours.

Though lots of imaging modalities are there for the diagnosis of spinal tumours, which includes Plain Radiographs, Contrast Myelography, CT Scan, CT Myelography, none of the above-mentioned modalities are comparable to MRI in evaluation of spinal tumours.(1)

With development of higher magnetic field strength, and especially with the advent of surface coils MRI with its inherent high contrast resolution, rapidity, non-invasive nature, multiplanar capability and virtually artifact free display of anatomy and pathology in the region of spine is proving to be the examination of choice for the evaluation of spinal tumours.

Unlike Myelography or CT Myelography, MR does not require lumbar puncture and intrathecal contrast administration, hence is devoid of complications related to Myelography procedures and that related to the contrast materials. Accurate localisation of the spinal tumour (Either extradural, intradural, extramedullary or intramedullary in location) is very essential and crucial for surgical planning. MRI combines the benefits of cross-sectional and multiplanar imaging, which provides an overview of entire spinal anatomy and pathology.

Variation in MR signal characteristics, anatomical changes of the surrounding structures and contrast enhancement help to locate exactly where the tumour is located and also tissue characterisation.(2)

In the present study we will analyse MRI features of spinal tumours in patients and an attempt will be made to prove that MRI is the most sensitive modality for the diagnosis of spinal tumour. Also, we will confirm the MRI findings with histopathological correlation wherever applicable.

\section{MATERIALS AND METHODS}

This prospective study was conducted in the Department of Radiodiagnosis, G. R. Medical College and J. A. Group of Hospitals in collaboration with Vidya MRI Centre, Gwalior, in suspected spinal tumours and their histopathological correlation done. All patients were referred for MR, because of clinical presentations including backache and/or neurological deficits from the Departments of Orthopaedics, Neurology and Neurosurgery. Patient's population included both males and females.
All patients underwent MR imaging examination using a GE 0.2 Tesla Signa Profile permanent magnet unit.

Sagittal and axial spin-echo (SE) T1W (TR, 450 - 600 msec; TE, 15 - $20 \mathrm{msec}$ ) and T2W (TR, 2000 - $3000 \mathrm{msec}$; TE, 80 - 100 $\mathrm{msec}$ ) precontrast images were obtained in all patients.

Gadopentetate dimeglumine enhanced sagittal and axial (SE) T1W (TR, 450 - $600 \mathrm{msec}$; TE, 15 - $20 \mathrm{msec}$ ) images were obtained in all patients of intradural tumours. After obtaining written informed consent, a standard Gd DTPA-dimeglumine solution was injected IV in a dosage of $0.1 \mathrm{mmol} / \mathrm{kg}$ body weight.

\section{Exclusion Criteria}

1. History of acute trauma.

2. Past history of lumbar spinal surgery.

3. Contraindication to MR imaging (e.g. pacemaker, metallic clips, etc.).

MR images were reviewed. Tumours are characterised in terms of their location, morphology, number, signal characteristics and post contrast (Gd-DTPA) enhancement. Tumour location is described in relation with the adjacent vertebral level and in addition whether the lesion is extradural, intradural extramedullary, intramedullary and intradural with extradural extension. Signal intensity of the tumour is compared with that of spinal cord and paraspinal muscles for each imaging sequence. The presence of tumour enhancement, character of tumour enhancement (Intense or moderate) and the definitions of the enhanced borders (Sharply or poorly defined) were assessed.

Associated changes in terms of cystic degeneration of tumour mass, haemorrhage, calcification or associated nontumoral cysts or syrinx (Especially in the intramedullary tumours) are also noted.

\section{Observations}

Of the 77 patients, $70 \%$ were males and $30 \%$ of patients were females. Of the 77 patients, 61 patients showed extradural tumours, 12 patients showed intradural extramedullary tumour and 4 patients showed intramedullary tumours.

In extradural tumours, metastases were the most common tumours followed by multiple myeloma. In intradural extramedullary tumours, nerve sheath tumour were most common (7 cases of 12) followed by meningiomas (3 cases of 12). In intramedullary tumours, astrocytoma was found in 2 patients and ependymoma was found in 2 patients. Overall, haemangiomas were the most common incidental finding. Metastases were the most common extradural tumours $(91.8 \%)$ followed by multiple myeloma (6.5\%); $55.3 \%$ of metastases were located at multiple sites followed by thoracic $(28.5 \%)$ and lumbar region (14.28\%). Haemangiomas were found in $19.8 \%$ patients. Nerve sheath tumour was the most common intradural extramedullary tumour (58.3\%) followed by meningioma (25\%); $85.7 \%$ of nerve sheath tumours were solitary and $14.3 \%$ were multiple; $66.6 \%$ of the solitary nerve sheath tumours were lumbar in location; 2 of the solitary nerve sheath tumours had extradural component as well. Meningiomas were solitary. All the 3 cases of meningiomas showed intense enhancement on post-contrast studies. Ependymoma and Astrocytoma constituted 50\% each of intramedullary tumours. Astrocytomas were thoracic in both 
cases, Ependymomas were cervical and lumbar in location in $50 \%$ of the cases.

Overall, MRI findings were correlated with histopathology in 72 patients out of 77 suggesting that MRI is $93.5 \%$ accurate in diagnosing spinal tumours as a whole.

In extradural tumours, 4 out of 56 suspected metastases were actually cases of Pott's spine, a suspected case of chordoma was actually a case of PNET (Primitive Neuroectodermal Tumours), whereas all suspected cases of multiple myeloma were correlated with histopathology suggesting that MRI is $91.8 \%$ accurate in diagnosing extradural tumours.

All intradural extramedullary and intramedullary tumours were correlated histopathologically suggesting 100\% accuracy of MRI for diagnosing these tumours.

\section{RESULTS}

\begin{tabular}{|c|c|c|}
\hline Age Incidence & Number & Percentage \\
\hline $0-20$ Years & 3 & $3.9 \%$ \\
\hline $21-40$ Years & 12 & $15.5 \%$ \\
\hline $41-60$ Years & 35 & $45.5 \%$ \\
\hline 61 Years and above & 26 & $33.7 \%$ \\
\hline Total & 77 & $100 \%$ \\
\hline \multicolumn{2}{|c|}{ Table I. Showing Age Distribution } \\
\hline
\end{tabular}

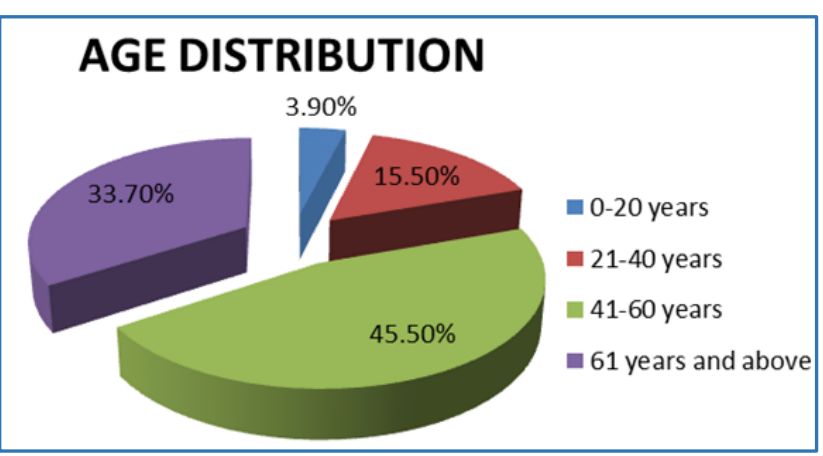

Figure I. Shows Occurrence of Spinal Tumours Maximum in Adults between 41 - 60 Years

\begin{tabular}{|c|c|c|}
\hline Sex & Number & Percentage \\
\hline Male & 54 & $70 \%$ \\
\hline Female & 23 & $30 \%$ \\
\hline Total & $\mathbf{7 7}$ & $\mathbf{1 0 0 \%}$ \\
\hline \multicolumn{3}{|c|}{ Table II. Showing Sex Ratio } \\
\hline
\end{tabular}

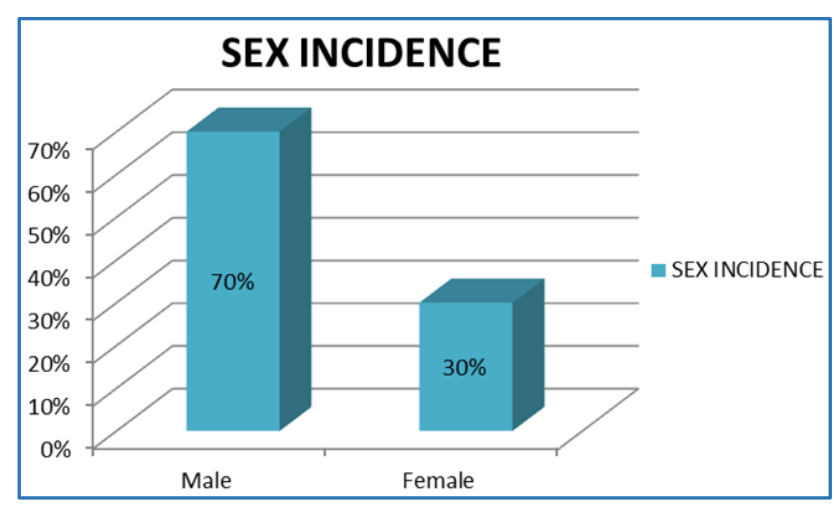

Figure II. Shows that the Number of Male Cases were More than the Females. The Male-to-Female Ratio is 2.3:1

\begin{tabular}{|c|c|c|}
\hline Tumour & Number & Percentage \\
\hline Extradural & 61 & $79.2 \%$ \\
\hline $\begin{array}{c}\text { Intradural } \\
\text { Extramedullary }\end{array}$ & 12 & $15.5 \%$ \\
\hline Intramedullary & 4 & $5.1 \%$ \\
\hline Total & 77 & $100 \%$ \\
\hline
\end{tabular}

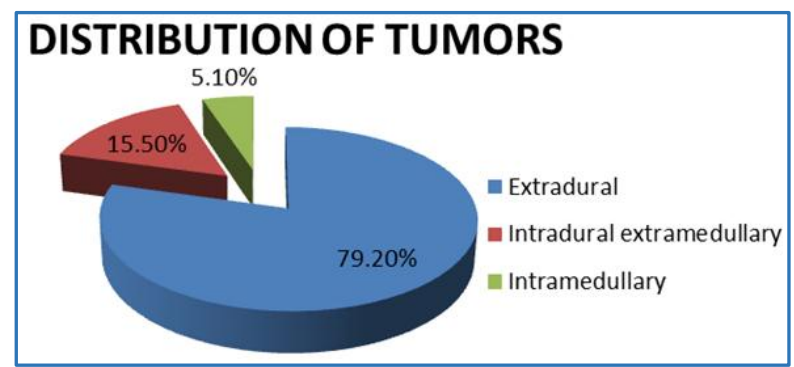

Figure III. Shows Maximum Number of Tumours are Extradural in Distribution

\begin{tabular}{|c|c|c|}
\hline Tumour & Number & Percentage \\
\hline Metastases & 56 & $91.8 \%$ \\
\hline Multiple Myeloma & 4 & $6.5 \%$ \\
\hline Chordoma & 1 & $1.6 \%$ \\
\hline Total & $\mathbf{6 1}$ & $\mathbf{1 0 0} \%$ \\
\hline Table IV. Showing Extradural Tumours \\
\hline
\end{tabular}

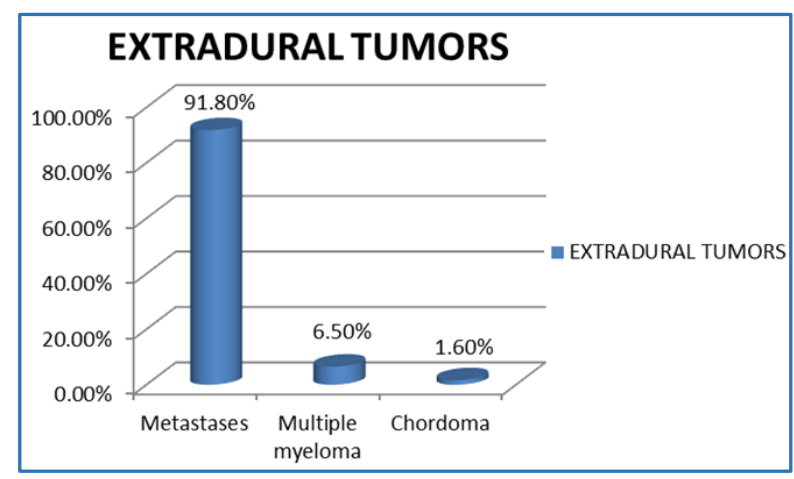

Figure IV. Shows Maximum Extradural Tumours were Metastases followed by Multiple Myeloma

\begin{tabular}{|c|c|c|}
\hline Tumour & Number & Percentage \\
\hline Nerve Sheath Tumour & 7 & $58.3 \%$ \\
\hline Meningioma & 3 & $25 \%$ \\
\hline Epidermoid Cyst & 1 & $8.3 \%$ \\
\hline Lipoma & 1 & $8.3 \%$ \\
\hline Total & 12 & $100 \%$ \\
\hline
\end{tabular}

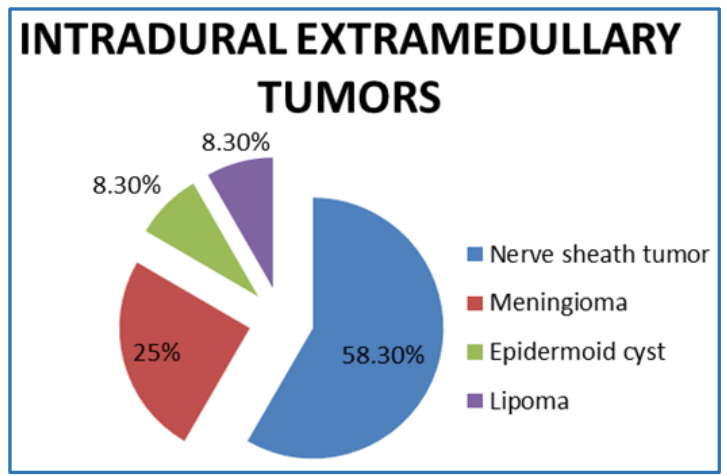

Figure V. Shows Maximum Intradural Extramedullary Tumours were Nerve Sheath Tumours followed by Meningioma 


\begin{tabular}{|c|c|c|}
\hline Tumour & Number & Percentage \\
\hline Ependymoma & 2 & $50 \%$ \\
\hline Astrocytoma & 2 & $50 \%$ \\
\hline Total & 4 & $100 \%$ \\
\hline
\end{tabular}

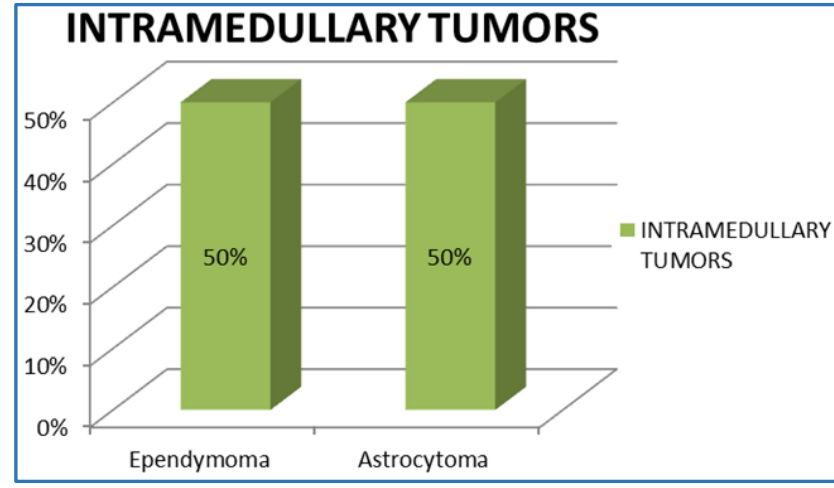

Figure VI. Shows Intramedullary Tumours which included Ependymoma and Astrocytoma

\begin{tabular}{|c|c|c|}
\hline Level & Metastatic Lesions & Percentage \\
\hline Multiple & 31 & $55.35 \%$ \\
\hline Cervical & 1 & $1.78 \%$ \\
\hline Thoracic & 16 & $28.57 \%$ \\
\hline Lumbar & 8 & $14.28 \%$ \\
\hline Sacral & 0 & $0 \%$ \\
\hline Total & $\mathbf{5 6}$ & $\mathbf{1 0 0} \%$ \\
\hline \multicolumn{2}{|c|}{ Table VII. Showing Location of Metastatic Lesions } \\
\hline
\end{tabular}

\section{DISTRIBUTION OF METASTATIC LESIONS}

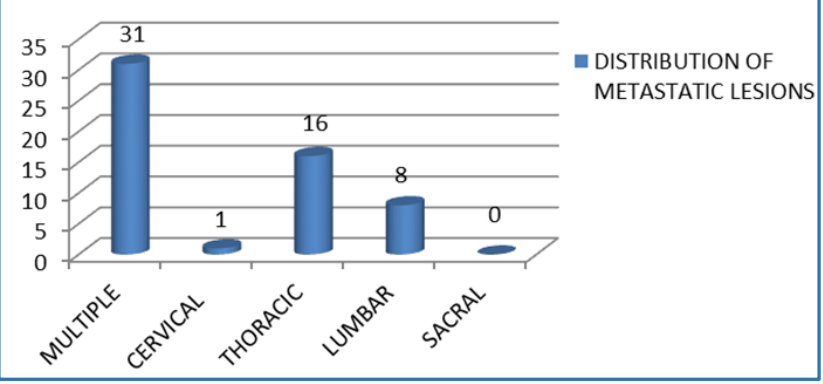

Figure VII. Shows that Maximum Metastatic Lesions were Found at Multiple Spinal Levels followed by Thoracic Spine and Lumbar Spine

\begin{tabular}{|c|c|c|c|c|}
\hline Tumour & Cervical & Thoracic & Lumbar & Total \\
\hline $\begin{array}{c}\text { Nerve Sheath } \\
\text { Tumour } \\
\text { (Solitary) }\end{array}$ & $1(16.6 \%)$ & $1(16.6 \%)$ & $4(66.6 \%)$ & $6(100 \%)$ \\
\hline Meningioma & $1(33.3 \%)$ & $2(66.6 \%)$ & 0 & $3(100 \%)$ \\
\hline $\begin{array}{c}\text { Epidermoid } \\
\text { Cyst }\end{array}$ & 0 & 0 & $1(100 \%)$ & $1(100 \%)$ \\
\hline Lipoma & $1(100 \%)$ & 0 & & $1(100 \%)$ \\
\hline \multicolumn{5}{|c|}{ Table VIII. Showing Location of } \\
Intradural Extramedullary Tumours
\end{tabular}

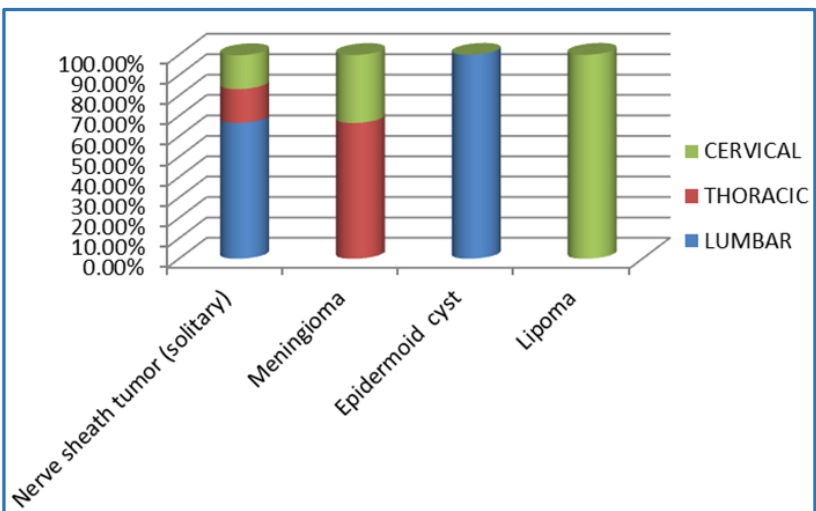

Figure VIII. Shows $66.6 \%$ of Solitary Nerve Sheath Tumours are Located in the Lumbar Region and Meningiomas are Located in the Cervical and Thoracic Region

\begin{tabular}{|c|c|c|c|c|}
\hline Tumour & Cervical & Thoracic & Lumbar & Total \\
\hline Ependymoma & $1(50 \%)$ & 0 & $1(50 \%)$ & 2 \\
\hline Astrocytoma & 0 & $2(100 \%)$ & 0 & 2 \\
\hline
\end{tabular}

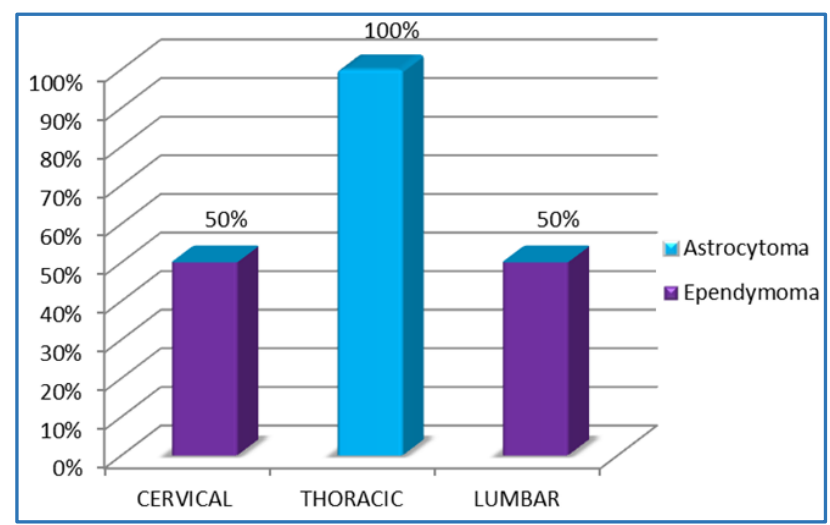

Figure IX. Shows that all the Astrocytomas were Thoracic in Location, whereas 50\% Ependymomas were Lumbar and Cervical in Location

\begin{tabular}{|c|c|c|}
\hline $\begin{array}{c}\text { Nerve Sheath } \\
\text { Tumour }\end{array}$ & Number & Percentage \\
\hline Solitary & 6 & $85.7 \%$ \\
\hline Multiple & 1 & $14.3 \%$ \\
\hline Total & $\mathbf{7}$ & $\mathbf{1 0 0 \%}$ \\
\hline \multicolumn{2}{|c|}{ Table X. Showing Solitary/ } \\
Multiple Nerve Sheath Tumours \\
\hline
\end{tabular}

\section{Nerve Sheath Tumors}

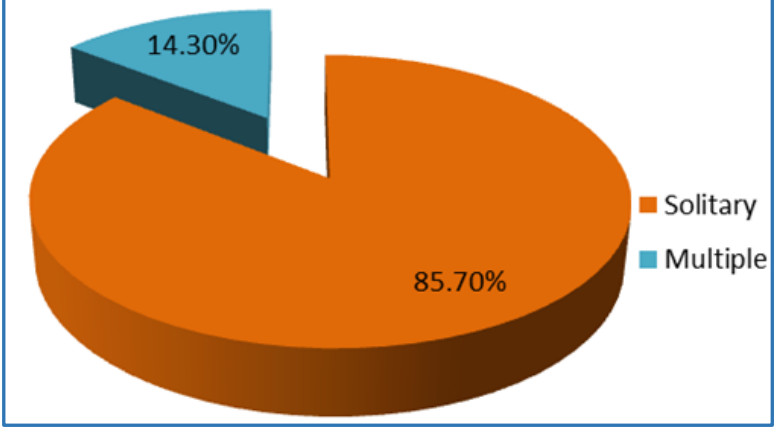

Figure X. Shows $14.3 \%$ of the Nerve Sheath Tumours were Multiple, $85.7 \%$ were Solitary 


\begin{tabular}{|c|c|c|}
\hline Nerve Sheath Tumour & Number & Percentage \\
\hline Intradural Extramedullary & 5 & $71.42 \%$ \\
\hline $\begin{array}{c}\text { Intradural Extramedullary } \\
\text { with Extradural Component }\end{array}$ & 2 & $28.58 \%$ \\
\hline Extradural & 0 & 0 \\
\hline Intramedullary & 0 & 0 \\
\hline Total & 7 & $\mathbf{1 0 0} \%$ \\
\hline Table XI. Showing Distribution of Nerve Sheath \\
Tumours \\
\hline
\end{tabular}

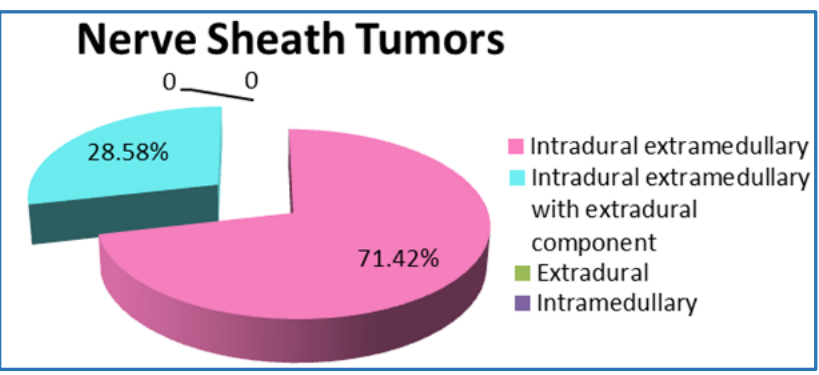

Figure XI. Showing $71.42 \%$ of the Nerve Sheath Tumours were Intradural Extramedullary in Distribution and $28.58 \%$ were Intradural Extramedullary with Associated Extradural Component

\begin{tabular}{|c|c|c|c|}
\hline \multirow{2}{*}{ Tumour } & \multicolumn{3}{|c|}{ Enhancement Pattern } \\
\cline { 2 - 4 } & $\begin{array}{c}\text { No } \\
\text { Enhancement }\end{array}$ & $\begin{array}{c}\text { Moderate } \\
\text { Enhancement }\end{array}$ & $\begin{array}{c}\text { Intense } \\
\text { Enhancement }\end{array}$ \\
\hline $\begin{array}{c}\text { Nerve } \\
\text { Sheath } \\
\text { Tumour }\end{array}$ & 0 & $1(14.28 \%)$ & $6(85.7 \%)$ \\
\hline Meningioma & 0 & 0 & $3(100 \%)$ \\
\hline $\begin{array}{c}\text { Epidermoid } \\
\text { Cyst }\end{array}$ & $1(100 \%)$ & 0 & 0 \\
\hline Lipoma & $1(100 \%)$ & 0 & 0 \\
\hline \multicolumn{4}{|c|}{$\begin{array}{c}\text { Table XII. Showing Enhancement Pattern } \\
\text { of Intradural Extramedullary Tumours }\end{array}$} \\
\hline
\end{tabular}

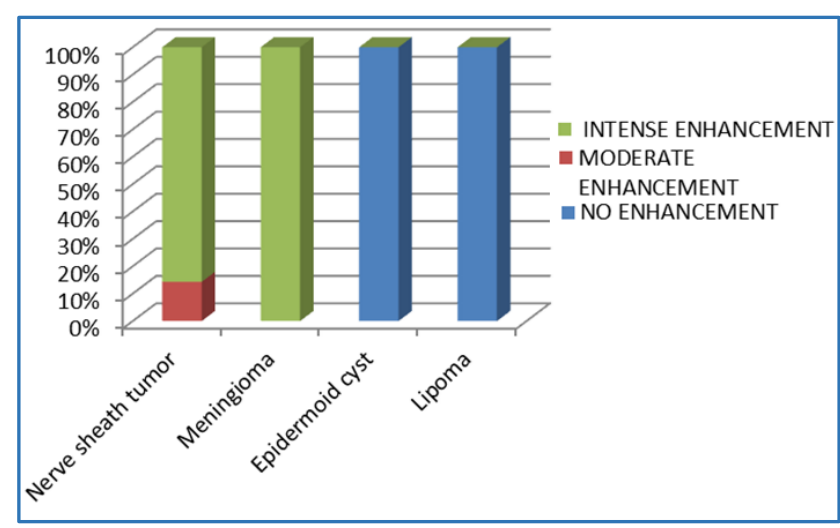

Figure XII. Showing $100 \%$ of the Meningiomas were Intensely Enhancing, 85.7\% of the Nerve Sheath Tumours were Intensely Enhancing. Epidermoid Cyst and Lipoma showed No Enhancement

\begin{tabular}{|c|c|c|c|}
\hline \multirow{2}{*}{ Tumour } & \multicolumn{3}{|c|}{ Enhancement Pattern } \\
\cline { 2 - 4 } & $\begin{array}{c}\text { No } \\
\text { Enhancement }\end{array}$ & $\begin{array}{c}\text { Moderate } \\
\text { Enhancement }\end{array}$ & $\begin{array}{c}\text { Intense } \\
\text { Enhancement }\end{array}$ \\
\hline Ependymoma & 0 & 0 & $2(100 \%)$ \\
\hline Astrocytoma & 0 & 0 & $2(100 \%)$ \\
\hline \multicolumn{3}{|c|}{ Table XIII. Showing Enhancement } \\
Pattern of Intramedullary Tumours \\
\hline
\end{tabular}

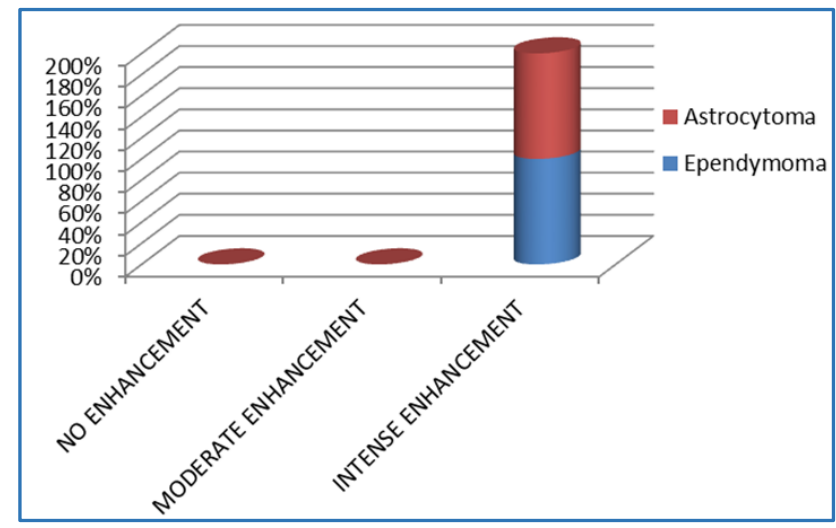

Figure XIII. Shows all Intramedullary Tumours show Intense Contrast Enhancement

\begin{tabular}{|c|c|c|}
\hline Tumour & Number & Percentage \\
\hline Haemangioma & 15 & $19.8 \%$ \\
\hline Total & 77 & $100 \%$ \\
\hline \multicolumn{2}{|c|}{ Table XIV. Showing Haemangiomas } \\
as an Incidental Finding \\
\hline
\end{tabular}

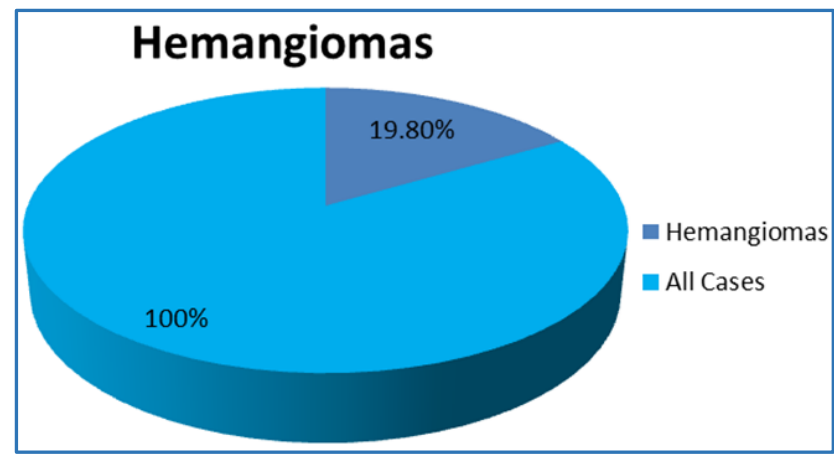

Figure XIV. Shows 19.8\% Haemangiomas as an Incidental Finding

\section{RESULTS}

\section{Metastases}

56 patients were studied, almost all patients had vertebral destruction with hypointense or combined hypo- and isointense signal relative to bone marrow on T1-weighted images. On T2-weighted images, the tumours were isointense or slightly hyperintense. It was usually impossible to differentiate the various tumours on the basis of signal intensity and morphology. However, metastases from suspected carcinoma of the prostate were often more hypointense than other tumours on T1- and T2-weighted images. The above-mentioned findings correlate well with studies conducted by M. H. Li, S. Holffts, E. M. Larsson.(3)

Of the 56 patients, 4 were known cases of CA Prostate, 3 were known cases of CA Breast and 1 was known case of CA lung.

52 were found to have metastases on histopathology and 4 were in fact cases of Pott's spine.

\section{Multiple Myeloma}

All 4 patients showed an inhomogeneous pattern in which diffusely low signal is combined with focal lower signal on $\mathrm{T} 1$ weighted images and higher signal is noted on T2-weighted. This correlate with the study of Ross J. S. et al.(4) However, the diagnosis was equivocal on MRI. 
All 4 patients were found to be cases of multiple myeloma on histopathology.

\section{Haemangioma}

Haemangiomas were noted as incidental findings in our study; 15 patients were studied and they show the classic vertical trabecular or radiating pattern of thickening with high signal intensity on T1- and T2-weighted images due to the presence of intratumoral fat. This correlate with the study of Joan C. Vilanova et al.(5)

\section{Chordoma}

A case of chordoma involving sacral spine was noted. It showed low signal on T1-weighted images and high signal on T2-weighted images. It correlated with the study of Ross J. S. et al.(4) On histopathology, however, it was found to be a case of PNET.

\section{Nerve Sheath Tumours}

Most of the 7 nerve sheath tumours showed hyperintense signal on T2W images, 2 tumour show central areas of decreased signal intensity on $\mathrm{T} 2 \mathrm{~W}$ images corresponding to denser areas of collagen and Schwann cells. Most of the tumours show intense enhancement. The above-mentioned findings correlate well with studies conducted by David Friedmann et al(6) and Hiroshi Demaschi et al.(7) Chung et al(8) found nerve sheath tumours comprised of $58.9 \%$ of all spinal cord tumours.

On histopathology, 5 tumours were found to be neurofibromas and 2 were schwannoma.

\section{Meningiomas}

All 3 cases of meningiomas were isointense to the spinal cord on T1W images and slightly hyperintense to isointense on $\mathrm{T} 2 \mathrm{~W}$ images. All of them showed intense enhancement on post contrast study. This correlate with the study shown by Gordon Sze et al.(9)

On histopathology, all tumours were found to be meningiomas.

\section{Epidermoid Cyst}

The case of epidermoid cyst in our study showed a moderate sized exophytic cystic mass, homogeneously hyperintense on $\mathrm{T} 2$ and hypointense on T1W images with mild peripheral enhancement seen in lower dorsal spine, extended from mid body of L1 to L3 vertebral body causing focal dilatation of thecal sac and leftward displacement of cord. This correlated with the study of Lunardi P. et al,(10) in which most of the cases were noted in lumbar spine. On histopathology, it was found to be epidermoid cyst.

Our study included 1 case of intradural extramedullary lipoma. It was isointense to fat on all sequences. On histopathology, it was found to be lipoma.

\section{Ependymomas}

Of the 4 intramedullary tumours, 2 were ependymomas; 1 of them were located in the lumbar spine and the other in cervical spine. Both the tumours were isointense to cord on $\mathrm{T} 1 \mathrm{~W}$ images and hyperintense on $\mathrm{T} 2 \mathrm{~W}$ images. One tumour showed heterogeneous signals, which represented hemosiderin. Similar findings of location, imaging characteristics especially the peripheral hypointense rim were shown in studies conducted by Yutaka Nemoto et al(11) and Parizel et al.(12)

Both tumours were found to be ependymomas on histopathology.

\section{Astrocytomas}

2 of 4 intramedullary tumours were astrocytomas. The tumours were hyperintense on $\mathrm{T} 2 \mathrm{~W}$ images and were located eccentrically unlike ependymomas. Both the Astrocytomas were located in the thoracic region. Both cases showed intense enhancement. One case had associated cystic component. Sloof et al(13) in their study had shown that commonest location of astrocytomas was in thoracic region. Farwell JR et al(14) in their study had shown that astrocytomas represent more than $50 \%$ of intramedullary tumours in children.

Seo et al(15) in their study has shown that enhancements of astrocytomas could be focal nodular, patchy, inhomogeneous diffuse or homogeneous diffuse. They also concluded that nonenhancing intramedullary tumours are not uncommon.

Both tumours were found to be astrocytomas on histopathology.

\section{DISCUSSION}

The present study includes 77 patients of spinal tumours in our own institute during last one year and were correlated with histopathological findings. The tissue specimen for histopathological diagnosis was obtained by FNAC/biopsy/surgical excision and all cases had confirmed histological diagnosis except for cases of haemangioma.

Of the 77 patients 61 patients showed extradural tumours, 12 patients showed intradural extramedullary tumour and 4 patients showed intramedullary tumours.

In extradural tumours, metastases were the most common tumours followed by multiple myeloma.

In intradural extramedullary tumours, nerve sheath tumour were most common (7 cases of 12) followed by meningiomas ( 3 cases of 12 ).

In intramedullary tumours, astrocytoma was found in 2 patients and ependymoma was found in 2 patients.

Overall, haemangiomas were the most common incidental finding.

\section{REFERENCES}

1. Osborn AG. Text book of neuroradiology. Mosby 1997.

2. Scott WA. Magnetic resonance imaging of the brain and spine. $2^{\text {nd }}$ edn. Lippincott Raven 1996.

3. Li MH, Holffts S, Larsson EM. MRI of extradural spinal tumours at 0.3 T. Neuroradiol 1993;35(5):370-4.

4. Ross JS. Neoplasms, pathways of spread. In: Ross JS, Brant-Zawadzki M, Moore KR, et al, ed. Diagnostic imaging: spine. Salt Lake City: Amirsys 2004:p. IV-1-2-IV1-5.

5. Vilanova JC, Barcelo' J, Smirniotopoulos JG, et al. Hemangioma from head to toe: MR imaging with pathologic correlation. Radiographics 2004;24(2):36784.

6. Friedman DP, Tartaglino LM, Flanders AE. Intradural schwannomas of the spine: MRI findings with emphasis on contrast enhancement characteristics. AJR 1992; 158(6):1347-50. 
7. Demachi H, Takashima T, Kadoya M, et al. MR imaging of spinal neurinomas with pathological correlation. J Comp Asst Tomogr 1990;14(2):250-4.

8. Chung JY, Lee JJ, Kim HJ, et al. Characterization of magnetic resonance images for spinal cord tumors. Asian Spine Journal 2008;2(1):15-21.

9. Sze G. Magnetic resonance imaging in the evaluation of spinal tumors. Cancer 1991;67(4 Suppl):1229-41.

10. Lunardi P, Missori P, Gagliardi FM, et al. Long-term results of the surgical treatment of spinal dermoid and epidermoid tumors. Neurosurgery 1989;25(6):860-4.

11. Nemoto $Y$, Inoue $Y$, Tashiro $T$, et al. Intramedullary spinal cord tumors: significance of associated hemorrhage at MR imaging. Radiol 1992;182(3):793-3.
12. Parizel PM, Baleriaux D, Rodesh G, et al. Gd-DTPAenhanced MR imaging of spinal tumors. AJNR 1989;152(5):1087-96.

13. Sloof JL, Kernohan JW, MacCarty CS. Primary intramedullary tumors of the spinal cord and filum terminale. Philadelphia: WB Saunders 1969.

14. Farwell JR, Dohrmann GJ. Intraspinal neoplasms in children. Paraplegia 1977;15(3):262-73.

15. Seo HS, Kim JH, Lee DH, et al. Nonenhancing intramedullary astrocytomas and other MR imaging features: a retrospective study and systematic review. AJNR 2010;31(3):498-503. 